\title{
Leukocytes and oxidative stress: dilemma for sperm function and male fertility
}

\author{
Ralf R Henkel
}

Spermatozoa are constantly exposed to the interphase between oxidation through high amounts of reactive oxygen species (ROS) and leukocytes, and reduction by means of scavengers and antioxidants. Considering the very special functions as being the only cells with such high polarization and exerting their functions outside the body, even in a different individual, the female genital tract, the membranes of these cells are chemically composed of an extraordinary high amount of polyunsaturated fatty acids. This in turn, renders them very susceptible to oxidative stress, which is defined as an imbalance between oxidation and reduction towards the oxidative status. As a result, ROS deriving from both leukocytes and the male germ cells themselves cause a process called 'lipid peroxidation' and other damages to the sperm cell. On the other hand, a certain limited amount of ROS is essential in order to trigger vital physiological reactions in cells, including capacitation or the acrosome reaction in sperm. The treatment of patients with antioxidants to compensate the oxidative status caused by oxidative stress is highly debated as uncontrolled antioxidative treatment might derail the system towards the reduced status, which is also unphysiological and can even induce cancer. This paradox is called the 'antioxidant paradox'.

Therefore, a proper andrological diagnostic work-up, including the evaluation of ROS levels and the antioxidant capacity of the semen, has to be carried out beforehand, aimed at keeping the fine balance between oxidation and scavenging of vital amounts of ROS. Asian Journal of Andrology (2011) 13,43-52; doi:10.1038/aja.2010.76; published online 15 November 2010

Keywords: antioxidants; balance; beneficial effects; detrimental effects; leukocytes; male infertility; reactive oxygen species; sperm functions

\section{INTRODUCTION}

In 1943, the Scottish scientist John MacLeod made the ground-breaking observation that human spermatozoa produce reactive oxygen species (ROS), i.e., highly reactive derivatives of oxygen such as hydrogen peroxide $\left(\mathrm{H}_{2} \mathrm{O}_{2}\right)$, and that these substances have harmful effects on various sperm functions. ${ }^{1}$ In more recent years, scientists revealed that ROS not only negatively impacted on the fertilization process, but also raised serious questions about the health and well-being of the progeny if the male germ cell was exposed to high concentrations of oxidants. $^{2-4}$ This concept that oxidative stress causes damage to spermatozoa by impairing various sperm functions like motility, acrosome reaction or DNA integrity is now widely accepted. ${ }^{5-10}$

On the other hand, a considerable amount of work substantiated that very low, controlled amounts of oxidants appeared to be essential for normal physiological functioning of the male germ cell, thus having vital positive effects for various sperm functions like motility, capacitation or the induction of acrosome reaction. ${ }^{11-15}$ Hence, there is reason to believe that ROS also play an important role in cell signaling and specific activation of different physiological processes which often utilize redox-regulated signal transduction pathways. ${ }^{16-18}$

Because of these ambivalent functions of reactive oxygen species on sperm physiology as well as the very special nature of the male germ cell, a risk-benefit estimation for these potentially pernicious molecules has to be performed. Therefore, it is the aim of this report to highlight this delicate balance between beneficial and detrimental effects of ROS and shed light on the nature and origin of ROS, sperm morphology, functions and physiology as well as on the various mechanisms available in the male and female organism to keep this balance at physiological levels. For the comprehension of sperm physiology as well as the fertilization process, one needs to realize that a physiological or pathological imbalance of this redox equilibrium for spermatozoa can either activate the male germ cells or eliminate them from the system by making them dysfunctional or eliminate them totally by the phagocytotic action of activated leukocytes, which are present in the genital tract of both male and female. Essentially, one has to understand that oxygen is actually a double-edged sword; on the one hand, oxygen is crucial for life on earth and derivatives are fundamental for the induction of signal transduction cascades in certain physiological processes, but on the other hand, the element and its derivatives are detrimental to cells, including spermatozoa. This is called the 'oxygen paradox'. ${ }^{19,20}$

\section{SPERM MORPHOLOGY AND MEMBRANE LIPID COMPOSITION} Sperm morphology

During spermiogenesis, i.e., the process of sperm elongation, the male germ cell undergoes dramatic morphological changes whereby the spermatozoon gains its specific shape. Together with these morphological changes, the nucleus condenses and the flagellum extends 


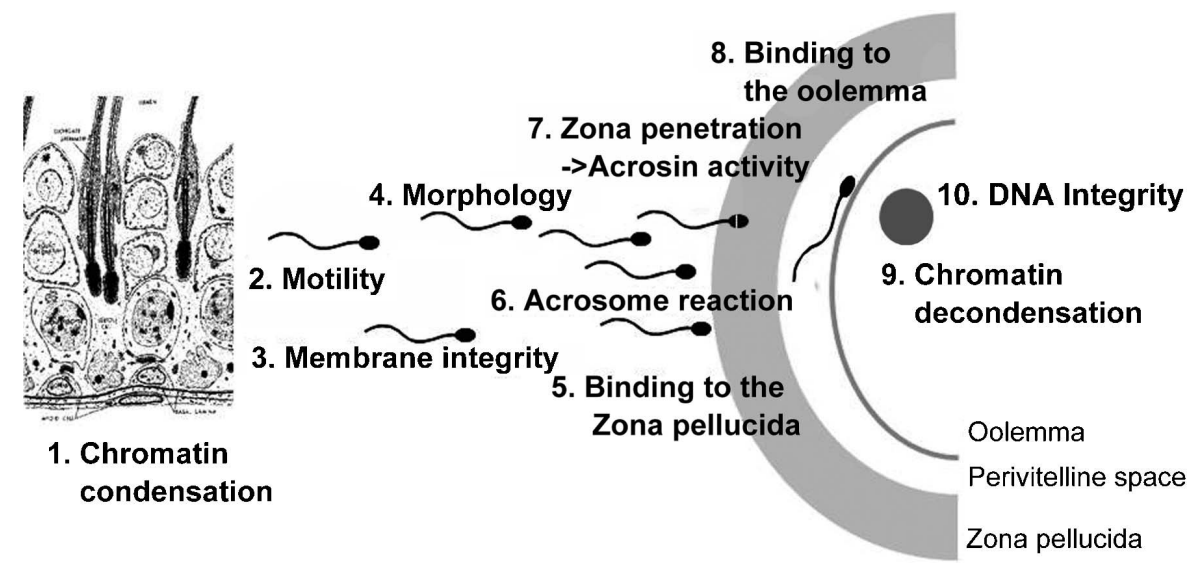

Figure 1 Schematic depiction of sperm functional parameters.

rendering the male germ cell not only the smallest cell in the human body, but also the most polarized cell (sperm head versus flagellum) with a diameter in the sperm head region of about $2.6-3.1 \mu \mathrm{m}$ and an overall length of about 54.5-61.5 $\mu \mathrm{m}^{21,22}$ Sperm elongation goes along with a dramatic loss of most of the cytoplasm, which in any cell contains intracellular scavengers to counteract oxidative stress, and is phagocytosed by Sertoli cells. Consequently, spermatozoa exhibit an inevitable lack of intrinsic antioxidative protection by ROS scavengers like catalase, glutathione peroxidase or superoxide dismutase as well as non-enzymatic molecules such as vitamins $\mathrm{C}$ or $\mathrm{E}$ or glutathione, which counteract the deleterious effects of oxidants in all aerobic cells.

Moreover, the male germ cell is the only cell that fulfills its functions extracorporally, even in a different individual, in the female genital tract whereby the male genetic information in the form of the genome is transported to the oocyte. For this, apart from covering a comparatively large distance of about $16-24 \mathrm{~cm}$ in the human from the vagina to the ampulla of the Fallopian tube, where fertilization takes place, the male germ cells have to interact with the oocyte and overcome various physiological barriers, namely, the cumulus oophorus, zona pellucida and oolemma. Thus, the sperm cells' obvious characteristics and functions (Figure 1) are their ability to move and to bind to and penetrate the oocyte vestments. These sperm functions are closely associated with the high compartmentalization of these cells (sperm head as 'container' for the genome and the acrosome as 'interacting device' with the oocyte; neck piece of the flagellum as 'connector'; mid-piece of the flagellum with mitochondria as 'power house' and the principal piece of the flagellum as main generator of sperm motility), which, compared with any other cell, comes along with a dramatic lack of cytoplasm as well as their specifically composed plasma membrane. Both these morphological and chemical characteristics are essential for normal sperm functions.

The extreme polarization of the male germ cell can only be properly maintained by a highly fluid plasma membrane. ${ }^{23,24}$ Since sperm functions mainly have to be regarded as membrane functions, ${ }^{25-27}$ membrane integrity is directly related to normal sperm functions. ${ }^{28-30}$ Consequently, normal sperm functions are, among others, determined by the composition of the plasma membrane lipids, which can be divided into phospholipids, neutral lipids and glycolipids. ${ }^{24}$ The phospholipids can be subdivided into phosphoglycerolipids and sphingomyelin, of which the composition of phosphoglycerolipids varies considerably among different mammalian species and shows an extraordinary high content of polyunsaturated fatty acids (Table 1). ${ }^{31}$
Importance of sperm plasma membrane and lipids for sperm functions

Owing to its special functions, the plasma membrane of spermatozoa, in contrast to somatic cells, exhibits a very special composition of phospholipids, sterols and saturated as well as polyunsaturated fatty acids (PUFAs). Human sperm plasma membranes show a high content of unsaturated fatty acids, which amount to about $50 \%$ of the total content of fatty acids. Particularly high is the percentage of docosahexaenoic acid (DHA), a PUFA containing six double bonds per molecule, ${ }^{32}$ which makes up about $21 \%$ of the total fatty acid and $43 \%$ of the PUFA content of human spermatozoa (Table 1). ${ }^{33}$

During recent years, the PUFA content in patients with oligozoospermia and/or asthenozoospermia was debated since different groups presented conflicting data with good arguments. On the one hand, Zalata et al., ${ }^{27}$ Lenzi et al. ${ }^{34}$ and Tavilani et al. ${ }^{35}$ reported that the PUFA levels in poorly motile sperm as well as patients' sperm were significantly lower, which would contribute to the poor motility in asthenozoospermic samples and even in patients with male genital tract infection. These data were corroborated by both the observations that

Table 1 Most important lipids present in the human sperm plasma membrane (according to Zalata et al. ${ }^{27}$ and Sanocka and Kurpisz ${ }^{33}$ )

\begin{tabular}{lrcc}
\hline Component & $\begin{array}{c}n \text { mol/108 } \\
\text { sperm }\end{array}$ & $\begin{array}{c}\text { \% of total } \\
\text { fatty acids }\end{array}$ & $\%$ \\
\hline Phospholipids & & & \\
$\quad$ Choline diacylglycerophospholipid & 37.0 & - & - \\
Ethanolamine diacylglycerophospholipid & 31.5 & - & - \\
$\quad$ Ethanolamine plasmalogen & 20.0 & - & - \\
$\quad$ Sphingomyelin & 20.0 & - & - \\
$\quad$ Choline plasmalogen & 12.5 & - & - \\
Fatty acid composition of phospholipids & & & \\
$\quad$ Saturated fatty acids (SFA) & & 49.95 & of SFA \\
$\quad$ Palmitic acid (C16) & 105.5 & 29.73 & 59.52 \\
$\quad$ Stearic acid (C18) & 35.9 & 11.35 & 22.72 \\
$\quad$ Unsaturated fatty acids (UFA) & & 50.05 & of UFA \\
$\quad$ Docosahexaenoic acid (C22:6; $\omega 3)$ & 108.0 & 21.54 & 43.04 \\
$\quad$ Oleic acid (C18:1; $\omega 9)$ & 32.6 & 9.17 & 18.32 \\
$\quad$ Linoleic acid (C18:2; $\omega 6)$ & 23.2 & 3.91 & 7.81 \\
$\quad$ Arachidonic acid (C20:4; $\omega 6)$ & 20.1 & 2.39 & 4.77 \\
$\quad$ Icosatrienoic acid (C20:3; $\omega 6)$ & 14.9 & 2.71 & 5.41 \\
Sterols (neutral lipids) & & & \\
$\quad$ Cholesterol & 133.0 & - & - \\
$\quad$ Desmosterol & 78.5 & - & - \\
Glycolipids & 6.4 & - & - \\
\hline
\end{tabular}


the mean melting point of fatty acids, an index of membrane fluidity, was significantly higher in these patients ${ }^{32}$ and saturated fatty acids predominate in the caput epididymis, ${ }^{36}$ which, in turn, is in line with the fact that caput epididymal sperm are immotile.

In contrast, Ollero et al. ${ }^{37}$ observed the highest levels of PUFAs, particularly DHA, in immature germ cells and spermatozoa. Similarly, Khosrowbeygi and Zarghami ${ }^{38}$ revealed that pathological semen samples with poor motility have higher PUFA levels, especially DHA, than normozoospermic samples. These authors conclude that because spermatozoa from pathological samples with poor motility have such high contents of PUFAs, these spermatozoa are much more susceptible to oxidative damage by ROS. In a very recent report, Koppers et al. ${ }^{39}$ confirmed these results and suggested that the reason for this high content of DHA in immature spermatozoa would lie in an aberrant transformation of defective germ cells during their morphogenesis leaving these cells with too high levels of PUFAs. Thus, an excess amount of unsaturated fatty acids appears to trigger mitochondrial ROS production and, therefore create oxidative stress for these spermatozoa, which results in functional damage. Koppers and co-workers ${ }^{39}$ interpret this discrepancy with the different endpoints used in the different studies. While Zalata et al. ${ }^{27}$ and Lenzi et al. ${ }^{34}$ measured the free fatty acids as percentage of the content, Ollero and co-workers ${ }^{37}$ determined the free fatty acid content per cell.

In light of the intrinsic lack of antioxidant protection combined with the extraordinary high lipid content of the plasma membrane, the male germ cell is extremely vulnerable to oxidative stress. Accordingly, these factors render these cells heavily dependent on antioxidative protection provided from the surrounding milieu, i.e., the epididymal fluid, seminal plasma as well as the fluids in the female genital tract. This is of particular importance since vagina and uterus are not immunologically privileged organs. Thus, specific mechanisms to protect the male germ cell and its functions must be provided by the male genital tract secretions in the seminal plasma as well as the female genital tract.

\section{WHAT ARE RADICALS AND ROS?}

From a chemical point of view, radicals are chemical intermediates that have one or more unpaired electrons. This chemical condition causes an electronically labile state and results in extreme reactivity of the respective molecules. Biologically important and relevant are free radical derivatives of oxygen $\left(\mathrm{O}_{2}\right)$ and nitrogen $\left(\mathrm{N}_{2}\right)$. These molecules are called ROS or reactive nitrogen species, of which only ROS are discussed in this report.

Molecular oxygen $\left(\mathrm{O}_{2}\right)$ itself has an unusual electronic structure; it is a paramagnetic diradical that has two unpaired electrons with parallel spins. Although oxygen is a diradical, its peculiar electronic structure makes molecular oxygen relatively non-reactive. Since a simultaneous introduction of two electrons into the molecule would contravene rules of quantum mechanics, additional electrons are introduced into the orbitals one by one resulting in the formation of reduced intermediates which are radicals, once this molecule reacts (Figure 2).

Examples of ROS relevant for spermatozoa are hydroxyl radicals $(\cdot \mathrm{OH})$, superoxide anion $\left(\cdot \mathrm{O}_{2}^{-}\right)$or hydrogen peroxide $\left(\mathrm{H}_{2} \mathrm{O}_{2}\right)$. ROS have a high oxidative potential and therefore very short half-life times in the nanosecond $\left(10^{-9} \mathrm{~s}\right)(\cdot \mathrm{OH}$; hydroxyl radicals $)$ to millisecond range $\left(10^{-3} \mathrm{~s}\right)\left(\cdot \mathrm{O}_{2}^{-}\right.$; superoxide anion $) .^{40}$ Therefore, these radicals practically react at the site of generation. On the contrary, some other oxygen intermediates like peroxyl (ROO·) and alkoxyl ( $\mathrm{RO} \cdot$ ) radicals, which can be formed in plasma membranes in the process of lipid peroxidation (LPO, see below), show half-life times even in the second range $(\mathrm{RO} \cdot: 7 \mathrm{~s})$ and are consequently comparatively stable. Thus,

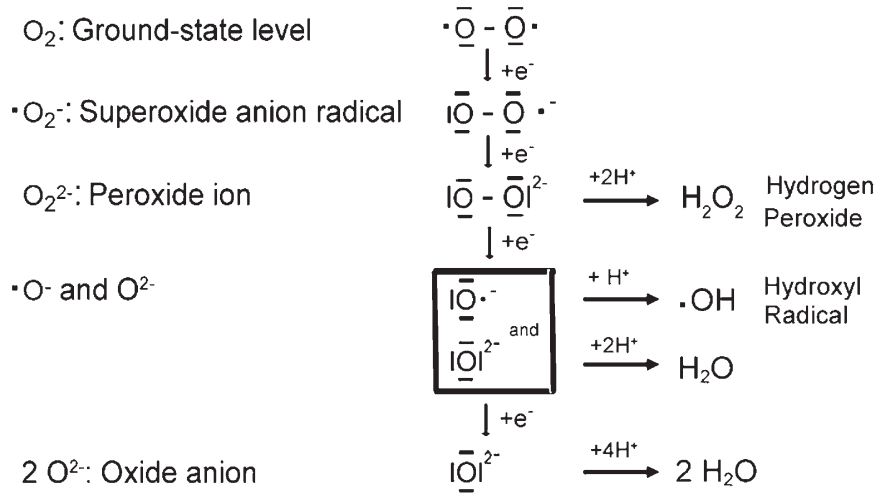

Figure 2 Oxidation forms of oxygen. If molecular oxygen, which is a diradical with two unpaired electrons, is reduced, it acquires four electrons and water $\left(\mathrm{H}_{2} \mathrm{O}\right)$ is formed. The dashes around the oxygen $(\mathrm{O})$ represent paired, the points represent unpaired electrons.

such molecules can travel some distances and exert their actions at other target sites.

In addition, another ROS, hydrogen peroxide $\left(\mathrm{H}_{2} \mathrm{O}_{2}\right)$, which is chemically not a radical as it does not have unpaired electrons, but is also highly reactive, is persistent and can freely penetrate plasma membranes because it is electronically not charged. It is harmful to spermatozoa from different species and their functions at high concentrations. ${ }^{1,41-44}$ Hydrogen peroxide derives from spontaneous or enzymatic dismutation of superoxide. In contrast, other ROS like superoxide anion or the hydroxyl radical are non-membrane permeable.

\section{ROS PRODUCTION IN HUMAN SPERMATOZOA}

Like in any other living cell, in spermatozoa energy is largely aerobically produced by means of enzymatically controlled mitochondrial oxidative phosphorylation and oxidation of hydrogen in the form of nicotinamide adenine dinucleotide $(\mathrm{NADH})$. Subsequently, the chemical energy is conserved as adenosine triphosphate. In the course of this stepwise process of the electron transfer chain, elementary oxygen $\left(\mathrm{O}_{2}\right)$ is taking up four electrons and is thus reduced to highly reactive free radicals as intermediate products. At the end of this process of oxygen reduction, water $\left(\mathrm{H}_{2} \mathrm{O}\right)$ is formed (Figure 2). Yet, mammalian spermatozoa may also obtain the metabolic energy in form of adenosine triphosphate via the Embden-Meyerhof-Parnas pathway (glycolysis). However, this is species-specific and dependent on the demands set in the female genital tract. ${ }^{45}$

In spermatozoa, a sperm-specific diaphorase (NADPH-dependent oxidoreductase $)^{46}$ is located in the sperm mid-piece of the flagellum. ${ }^{47}$ Furthermore, mitochondria in somatic cells have been shown to possess at least nine sites capable of producing superoxide radicals (Equation (1)), ${ }^{48}$ of which the Complex I (NADH dehydrogenase) and Complex III (coenzyme Q: cytochrome $c$-oxidoreductase) have been demonstrated in spermatozoa. ${ }^{5,49}$ Disruption and subsequent leakage of electrons from the mitochondrial electron transfer chain resulted in the generation of ROS from Complex I or III. ${ }^{49,50}$ Even in the course of normal physiological aerobic metabolism, about $1-5 \%$ of the consumed oxygen is converted into free radicals ${ }^{51,52}$ and ROS produced via this mechanism are normally regarded as cytotoxic byproducts that are involved in the etiology of disease and aging. ${ }^{53}$

$$
\mathrm{NADH}+2 \mathrm{O}_{2} \rightarrow 2 \cdot \mathrm{O}_{2}^{-} \mathrm{NAD}^{+}+\mathrm{H}^{+}
$$

The superoxide anion, in turn, dismutates under the influence of a scavenging enzyme, superoxide dismutase, into hydrogen peroxide 
(Equation (2)). Thus, spermatozoa are very professional and effective producers of ROS like superoxide and $\mathrm{H}_{2} \mathrm{O}_{2}$.

$$
2 \cdot \mathrm{O}_{2}^{-}+2 \mathrm{H}^{+} \rightarrow \mathrm{O}_{2}+\mathrm{H}_{2} \mathrm{O}_{2}
$$

Additionally, in vivo reactions of these ROS are coupled via the Fenton and Haber-Weiss reactions (Figure 3 ) in cycles where cofactors, particularly transition metal ions like $\mathrm{Fe}^{2+} / \mathrm{Fe}^{3+}$, accelerate the reaction in generating the most reactive hydroxyl radicals. Normally, the generation of these free radicals is regulated by scavengers like manganese superoxide dismutase, copper/zinc superoxide dismutase, glutathione peroxidase and catalase.

Considering that the spermatozoon's own ROS generation is fuelled by cytoplasmic glucose-6-phosphate dehydrogenase, ${ }^{54}$ it is apparent that sperm exhibiting excess residual cytoplasm, which is one characteristic of poor sperm morphology due to immaturity and affects sperm fertilizing potential, ${ }^{55}$ are deemed to generate excessive amounts of ROS themselves. ${ }^{54,56,57}$ There are also significant cell-tocell differences in ROS production in subsets of spermatozoa at different maturational stages. ${ }^{58}$ The clinical importance of the sperm's own ROS production was underlined by considerably stronger correlations between the percentage of ROS-producing spermatozoa and different parameters in the ejaculate including sperm motility. ${ }^{59}$ This is particularly important, as excessively ROS-producing sperm seem to damage themselves, especially their DNA.

\section{OTHER ORIGINS OF ROS AND OXIDATIVE STRESS}

\section{Leukocytes in the male genital tract}

In the male genital tract and the ejaculate, ROS are not only deriving from the spermatozoa but can also be generated by leukocytes, which physiologically produce even up to 1000 times more ROS than spermatozoa. ${ }^{60,61}$ This high ROS production by leukocytes plays a major role in infections, inflammation and cellular defense mechanisms. Basically, the cellular mechanisms for the generation of ROS in leukocytes and spermatozoa are the same, yet in leukocytes it is a physiological necessity to release large amounts of superoxide into phagocytic vesicles during the killing action of pathogens.

Leukocytes are present in the genital tract of both male and female, even in healthy, fertile individuals not having an infection. ${ }^{62}$ In cases of male genital tract infections and inflammations, however, fertility including sperm functions ${ }^{63,64}$ is seriously affected as clinical findings show oligozoospermia, asthenozoospermia or even azoospermia. ${ }^{65,66}$ These changes can be triggered in various ways, namely, direct action of the pathogens on spermatozoa via agglutination ${ }^{67}$ or indirectly by inducing inflammatory processes in the seminal tract by activating leukocytes. ${ }^{68}$ In non-selected cases, the prevalence of male genital tract infection-related infertility varies between 10 and $20 \%$ and amounts to up to $35 \%$ in a large study comprising of more than 4000 patients consulting for infertility. ${ }^{69}$ It also appears that bacterial infections have a more detrimental effect in fertility-compromised patients than in

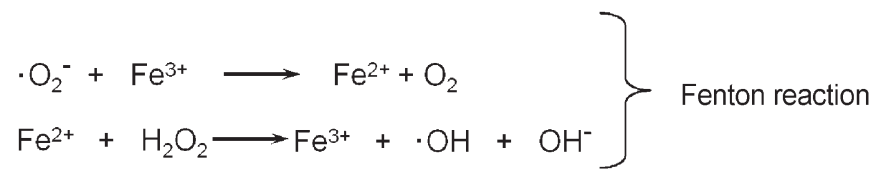

$\cdot \mathrm{O}_{2}^{-}+\mathrm{H}_{2} \mathrm{O}_{2} \stackrel{\mathrm{Fe}^{2+}}{\longrightarrow} \mathrm{O}_{2}+\mathrm{OH}^{-}+\cdot \mathrm{OH}$

Haber-Weiss reaction

Figure 3 Fenton and Haber-Weiss reaction. fertile men, ${ }^{70}$ indicating that the impact of such bacterial genital tract infections may have to be differentiated.

As a result of male genital tract infections/inflammations, activated leukocytes infiltrate the infected organs releasing high amounts of ROS, ${ }^{60}$ which have been shown to be associated with infertility by induction and stimulation of membrane LPO through oxidative stress. ${ }^{9,25,71}$ Through this mechanism, infections/inflammations do not only damage sperm DNA and reduce sperm count and seminal volume, but also impair sperm functions like motility, acrosome reaction or acrosin activity. ${ }^{59,72-77}$

\section{Leukocytes in the female genital tract}

Once they are ejaculated, spermatozoa are facing not only physical stress but also harsh environmental conditions in the female genital tract, which opens to the exterior and is therefore an entrance for pathogens to the female. Consequently, the vagina is well equipped with antimicrobial defense systems, which include a $\mathrm{pH}$ lower than 5 and immunological defense by leukocytes as spermatozoa are allogenic to the female. ${ }^{78}$ Although some antibacterial and antioxidative protection to spermatozoa is provided by the seminal plasma, ${ }^{79-82}$ and sperm initially outnumber the leukocytes present in vagina and cervix, they have to 'escape' the increasing number of leukocytes. Already 5-10 min after insemination spermatozoa have been recovered from the oviducts of inseminated women. ${ }^{83}$ Hence, rapid sperm transport from the site of semen deposition to the Fallopian tube is aided by the female organism for the male germ cells to overcome the female immunological defense. In addition, once sperm move out of the protective seminal plasma, they are progressively loosing the protection in terms of scavengers for ROS like spermine ${ }^{79,80}$ or uric acid ${ }^{84}$ which are abundantly provided in the seminal fluid. Spermatozoa therefore become increasingly susceptible to attack by leukocytes that eventually outnumber spermatozoa. ${ }^{85}$ On the other hand, a recent report by Navarrete Gomez et al. ${ }^{86}$ indicates that human tubular fluid appears to contain a protective compound against leukocyte-induced sperm DNA damage. Yet, the nature of this protective factor is still unknown.

\section{Other sources of ROS}

Besides ROS coming from leukocytic attacks to spermatozoa in the male and female genital tracts due to infection/inflammation and immunological stimulation, spermatozoa are facing ROS deriving from exogenous sources. These include environmental pollutants like heavy metals, pesticides or phthalate, a compound that is frequently found in plastic articles or cosmetics. Furthermore, smoking, alcohol, varicocele or spinal cord injuries contribute to such oxidative stress. For all these environmental and lifestyle factors, the impairment of fertility through ROS generation and subsequent oxidative stress has been reported. ${ }^{87-93}$

\section{OXIDATIVE STRESS}

Considering that any living cell functions in a chemically rather reduced status, it is of utmost importance that the equilibrium between oxidants and antioxidants is finely balanced and kept in a steady state. This reduced status is maintained by various antioxidative systems, both enzymatic and non-enzymatic. While glutathione peroxidase and superoxide dismutase are most common among the enzymatic systems, ${ }^{94}$ vitamins like vitamin A, C or E represent important non-enzymatic antioxidants. ${ }^{95}$ Thus, cells are constantly facing the interface between the oxidative and reductive status. In cases where this steady state derails for whatever reason an imbalance in favor of 
oxidants is created, which can then potentially cause cellular or genetic damage, this condition is called 'oxidative stress' ${ }^{96}$

\section{DETRIMENTAL EFFECTS OF ROS AND LEUKOCYTES}

Considering the extraordinary high content of PUFA described above, the sperm plasma membrane is particularly susceptible to oxidative stress and the double bonds of the membrane lipids can easily be oxidized by excessive ROS levels present in the sperm cells' environment. These can either be produced in large amounts by leukocytes or the spermatozoa themselves. In case of ROS attacking the plasma membrane lipids, a process called 'lipid peroxidation' (LPO) is initiated. Ultimately, this process decreases membrane fluidity of both plasma and organelle membranes and, as a result, damages membrane function, ion gradients, receptor-mediated signal transduction, etc. ${ }^{97}$ Hence, with the loss of membrane function, spermatozoa lose the ability to function properly and therefore, fertilization is impaired. ${ }^{98}$

\section{Lipid peroxidation}

The LPO has three phases, namely, the initiation, propagation and termination phase. During the initiation phase, highly reactive ROS such as $\mathrm{OH} \cdot$ or the hydroperoxyl radical $\left(\cdot \mathrm{HO}_{2}\right)$ attack the PUFA at carbon atoms adjacent to the double bonds leading to hydrogen abstraction from neighboring methylene groups, which are especially reactive, and the creation of a lipid radical and water. The free electron is transferred to the lipid (Figure 4a). Less reactive ROS like $\mathrm{H}_{2} \mathrm{O}_{2}$ are not able to initiate this reaction. ${ }^{99}$ This newly generated lipid radical will then be stabilized in so-called resonance structures by delocalization of the free electron, which is an energetically more stable structure than the initiating ROS. Yet, the lipid radical is also not a very stable molecule. Subsequently, the lipid radical reacts spontaneously with molecular oxygen to form a lipid peroxide.

In the propagation phase, the reactive lipid peroxide radical molecule reacts with another neighboring fatty acid producing another fatty acid radical, which, in turn, reacts with molecular oxygen to form another lipid peroxide. This mechanism is called 'radical chain reaction' and results in the propagation of the damage to not only one or few lipid molecules by one initiating radical molecule, but to numerous molecules. As a result, the LPO process can oxidize almost $60 \%$ of the unsaturated fatty acid contend present in the plasma membrane. ${ }^{100}$
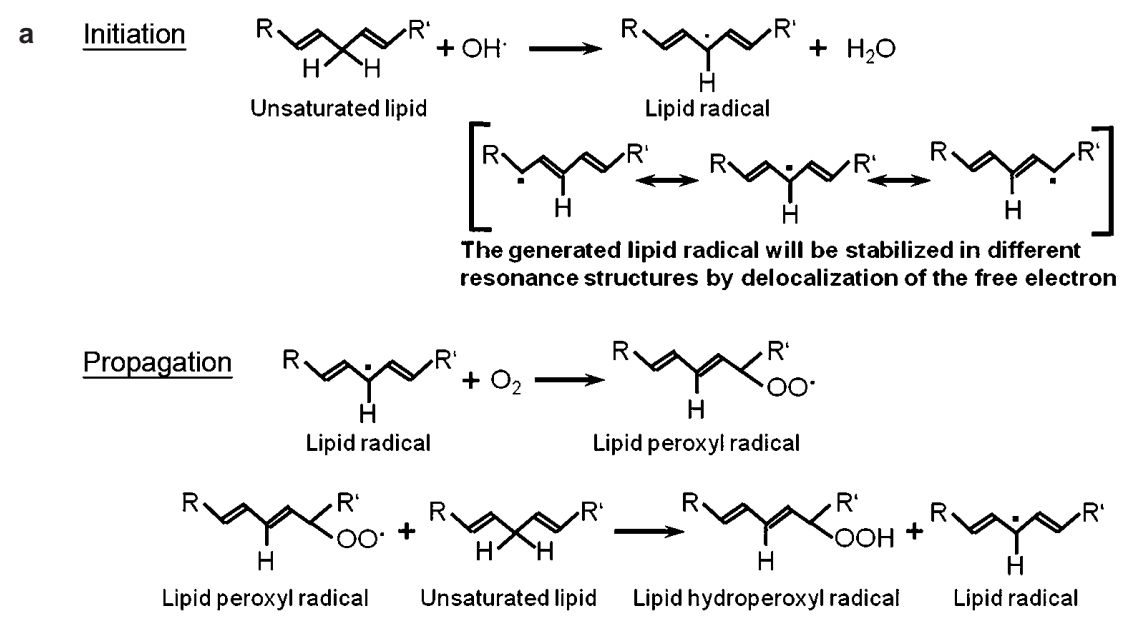

b Termination
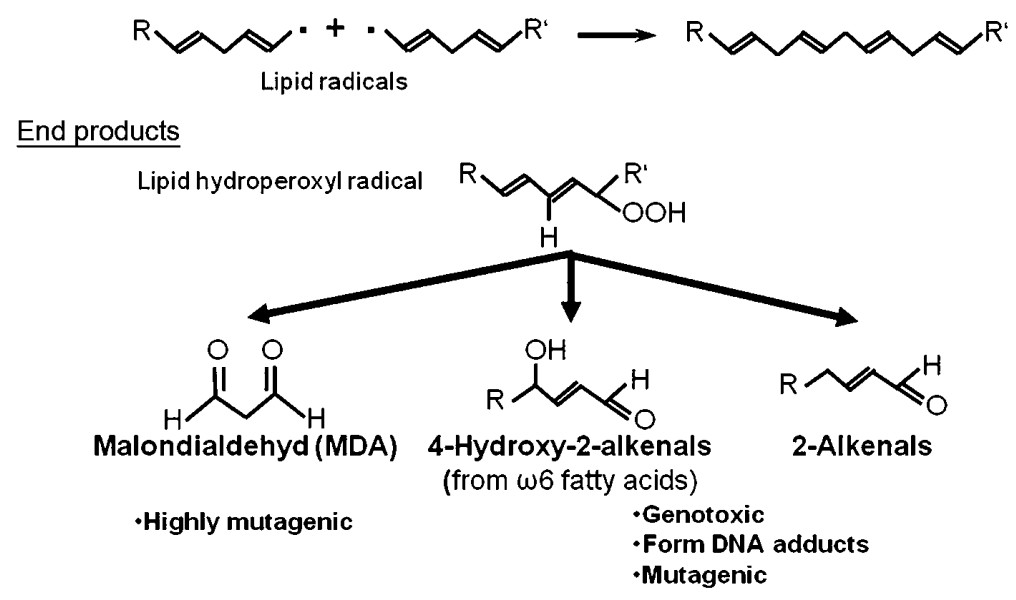

Figure 4 Chemistry of lipid peroxidation. (a) Initiation and propagation phases by radicals. In the initiation phase, the lipid radical is stabilized in different resonance structures by delocalization of the free electron. In the propagation phase, the lipid radical reacts with molecular oxygen to form a lipid peroxyl radical which propagates the reaction by means of a radical chain reaction. (b) In the termination phase, two lipid radicals react with one another to form a stable bond. Also, from lipid hydroperoxyl radicals, a variety of degradation products like malondialdehyde, 4-hydroxy-2-alkenals or 2-alkenals are formed. These end products are mutagenic and genotoxic. 
The propagation of LPO comes to an end when one radical reacts with another radical, thus producing a non-radical, stable product whereby the two free electrons from the two radicals form a covalent bond. This termination phase starts when a high concentration of lipid radicals is available so that the probability that two radicals can react is high. During LPO, lipid molecules are broken down and numerous stable carbonyl-containing by-products such as malondialdehyde and 4-hydroxy-2-alkenals such as 4-hydroxy-nonenal, resulting from $\omega 6$ fatty acids like docosahexaenoic acid, are formed. While MDA is highly mutagenic, 4-hydroxy-nonenal is most genotoxic. ${ }^{101}$ Consequently, the by-products of LPO pose another danger to spermatozoa, namely, cytotoxicity and DNA damage by forming DNA adducts. ${ }^{102}$ Thus, LPO is not only directly damaging membranes and therefore membrane functions, but also indirectly causing DNA damage (Figure $4 \mathrm{~b}$ ).

Recent studies clearly point out these relationships in different groups of patients. For instance, Khosrowbeygi and Zarghami ${ }^{38}$ showed that sperm from asthenozoospermic, asthenoteratozoospermic and oligoasthenoteratozoospermic patients had significantly higher PUFA levels in their plasma membranes than normozoospermic men and were therefore much more susceptible for oxidative stress and LPO. Furthermore, abnormal semen samples showed significantly higher malondialdehyde levels compared to the controls and correlated negatively with the sperm count, ${ }^{103}$ while in another study the sperm concentration of malondialdehyde (thiobarbituric acid reactive substance; TBARS concentration) was negatively correlated with fertilization rates in an in vitro fertilization program. ${ }^{104}$

Under normal conditions living organisms have developed protective strategies and mechanisms to minimize or avoid this LPO-initiated damage by very quick termination of the radical chain reactions by scavenging the free radicals with antioxidants. The most important physiological scavengers are vitamins $\mathrm{C}$ and $\mathrm{E}$ as well as antioxidant enzymes including superoxide dismutase, catalase and glutathione peroxidase. However, due to the genotoxicity and mutagenicity of 2-alkenals and 4-hydroxy-2-alkenals and their ability to form DNA adducts, it is obvious that the assumption that the antioxidants completely scavenge and therefore balance the effects of ROS and LPO is no longer valid. Hence, the cellular defense system is not $100 \%$ efficient (reviewed in Ref. 105).

\section{Other detrimental effects of ROS on sperm functions}

Among other factors, the different physicochemical behavior of different $\operatorname{ROS}\left(\mathrm{H}_{2} \mathrm{O}_{2}\right.$ versus $\mathrm{OH} \cdot$ or $\left.\cdot \mathrm{O}_{2}{ }^{-}\right)$is the reason for a differentiated action of membrane permeable and non-membrane permeable ROS on different sperm functions like motility or DNA integrity. Also, the location of the production, extrinsic by leukocytes or intrinsic by the male germ cells themselves, appears to play a role as extrinsic ROS produced by leukocytes rather impairs sperm motility, while intrinsic ROS production seems to preferentially affect sperm DNA fragmentation. ${ }^{75}$ On the other hand, a recent study (Mupfiga C, Henkel R, unpubl. data, 2010) revealed that the seminal leukocyte concentration not only correlated positively with ROS production in the ejaculate, but also with the sperm cell's own superoxide production $(r=0.336 ; P=0.0098 ; n=60)$, spermatozoa activation of the effector caspases-3/-7 ( $r=0.527 ; P<0.0001 ; n=58)$ as well as the percentage of sperm with disrupted mitochondrial membrane potential $(r=0.465 ; P=0.043 ; n=20)$. This gives evidence that a male genital tract infection/inflammation can trigger programmed cell death, apoptosis, by means of activating the caspase system.

In patients with chronic pelvic pain syndrome, apart from having impaired sperm motility or morphology, ${ }^{106-108}$ a significantly reduced inducibility of the acrosome reaction has been shown in both categories, inflammatory (NIH IIIA) and non-inflammatory prostatitis. ${ }^{76}$ As a possible cause for this acrosomal dysfunction, the detrimental influence of ROS and a reduced total antioxidative capacity in the semen of these patients has been suggested, while the mechanism of action would most probably function via the destabilization of the sperm plasma membrane by LPO.

\section{BENEFICIAL EFFECTS OF ROS AND LEUKOCYTES}

Although most reports published point out the detrimental effects of ROS, leukocytes and oxidative stress on sperm functions and thus on sperm fertilizing potential, pioneering work by the Gagnon and de Lamirande's group ${ }^{11,12}$ revealed that the superoxide anion in fact not only shows detrimental effects on sperm, but also plays an essential role in triggering cellular events like capacitation and hyperactivation, an essential requirement for sperm to penetrate the zona pellucida. ${ }^{109}$ Later work by the same group ${ }^{15,43,110}$ as well as by others ${ }^{13,14,111}$ confirmed these proposed functions not only for superoxide but also for other ROS like nitric oxide or hydrogen peroxide. Moreover, it could be shown that besides capacitation and hyperactivation, acrosome reaction, sperm zona binding and oocyte fusion are also stimulated by various low levels of ROS even in other species. ${ }^{56,112-114}$ More in-depth investigations revealed sperm activation by modulation of protein phosphorylation, which is also a key element in triggering acrosome reaction. ${ }^{13,14,115,116}$ Thus, capacitating sperm physiologically produce their own controlled amounts of ROS that in turn regulate downstream events such as an increase in cAMP, and protein kinase A activation with subsequent phosphorylation of its substrates. ${ }^{117}$

Therefore, despite the fact that excessive seminal production of ROS, either by leukocytes or the male germ cells themselves, are negatively correlated with sperm motility and concentration, ${ }^{63,118}$ it makes sense that the concentration of ROS in the medium after sperm separation is positively correlated with fertilization in vitro $(r=0.148$; $P=0.0454 ; n=183$ ). In addition, a positive trend of the sperm ROS production after sperm separation was observed with the four-cell stage formation after in vitro fertilization $(r=0.135 ; P=0.0695$; $n=183$ ) (Henkel et al., unpubl. data, 2005). In a subsequent ROCcurve analysis for fertilization, a cutoff value of $0.229 \times 10^{3} \mathrm{cpm} /$ $20 \times 10^{6}$ spermatozoa could be calculated.

If it is truly the case that even for fertilization in vitro a certain low amount of ROS is essential, one would have to be very careful in supplementing incubation media with antioxidants as it has been proposed recently. ${ }^{119}$ At least, the type of patient where such procedure would be beneficial would have to be selected very carefully beforehand because too high antioxidant concentrations in the insemination medium might then result in ROS concentrations that are too low for fertilization.

In contrast to the general view that leukocytes have a detrimental impact on sperm, ${ }^{74,120,121}$ even at concentrations as low as $2 \times 10^{4} \mathrm{ml}^{-1}$ after Percoll separation, ${ }^{122}$ and the sentiment that the current cutoff value for leukocytospermia of $1 \times 10^{6} \mathrm{ml}^{-1}$ given by the World Health Organization ${ }^{123}$ is too high, ${ }^{75,124-126}$ a few reports indicate no detrimental effect of leukocytes. ${ }^{122,127}$ Some recent reports even attribute significant positive effects to seminal leukocytes. ${ }^{128-130}$ Despite uncertainty regarding the levels of leukocyte contamination that are critical, the argument is that a certain elevated number of leukocytes is beneficial to sperm concentration, motility and acrosome reaction because leukocytes might eliminate defective spermatozoa by phagocytosis and may even stimulate sperm functions through the release of ROS. This idea would be supported by data published by 
Chakroun-Feki et al. ${ }^{131}$ who found that: (i) the presence of leukocytes in cervical mucus samples did not affect sperm motility; and (ii) the proportion of acrosome-reacted spermatozoa after sperm penetration of cervical mucus containing leukocytes was less pronounced, thus suggesting that low numbers of leukocytes in the cervical mucus could possibly influence or assist triggering capacitation.

Yet, high levels of leukocytes, particularly activated leukocytes, are still harmful to sperm functions. Consequently, one would have to see the presence of leukocytes in the ejaculate like ROS as a double-edged sword. This even more so as the negative impact of seminal ROS produced by leukocytes is depending on the total antioxidant capacity (TAC) of the ejaculate. ${ }^{132,133}$ In the light of individual variations in this parameter, one has to take the seminal redox status into account and future fertility analysis will have to take cognizance of this.

\section{PROTECTION OF SPERMATOZOA AGAINST OXIDATIVE STRESS}

Considering the vulnerability of spermatozoa to oxidative stress, the male germ cells have to be protected by relevant scavengers against these oxidants right from the site of sperm production, the testes, as developing spermatozoa during spermiogenesis have very limited ability to repair DNA and to replenish and regenerate glutathione. ${ }^{134}$ Here, the protection is given by the Sertoli cell, which provides a high level of the glutathione-dependent defense. ${ }^{135}$ Subsequently, in the epididymis, various members of the glutathione peroxidase family as well as catalase, indoleamine dioxygenase and superoxide dismutase have been identified as potential scavengers of ROS (reviewed in Ref. 136).

As mentioned before, seminal plasma contains large amounts of antioxidants to provide protection against oxidative stress in sperm cells. In fact, seminal fluid is the biological fluid that contains more antioxidant substances than any other physiological fluid does. The most important natural antioxidants in seminal plasma seem to be vitamins $\mathrm{C}$ and $\mathrm{E},{ }^{137,138}$ superoxide dismutase, ${ }^{139}$ uric acid, ${ }^{140}$ glutathione, ${ }^{141}$ glutathione peroxidase ${ }^{142}$ and the polyamine spermine (on average about $0.6 \mathrm{mg} \mathrm{ml}^{-1}$ ) that acts directly as a free radical scavenger and inhibits LPO. ${ }^{79,80}$

Apparently, the female genital tract is also providing antioxidant protection to spermatozoa against ROS and thereby sustaining normal sperm function, which is indeed a key element of the female reproductive system. Such a scavenger system has been shown in the Fallopian tube where epithelial cells protected sperm from ROSinduced damage. ${ }^{143}$ Recently, Navarrete Gomez and co-workers ${ }^{86}$ revealed that tubular fluid contains soluble, mainly non-enzymatic factors that inactivate leukocytic ROS.

\section{ANTIOXIDANT SUPPLEMENTATION AND 'ANTIOXIDANT PARADOX'}

Considering that modern lifestyle is characterized by a relatively low intake of natural antioxidants like vegetables or fruit, and a relatively high exposure to exogenous sources of ROS such as alcohol and cigarette consumption or environmental pollutants, many people are taking high dosages of antioxidants. This behavior is supported by advertising campaigns of companies and even doctors who prescribe antioxidants. Of course, this is done for a good reason to compensate the effects of lifestyle-derived ROS by artificial sources of antioxidants like vitamin tablets or other supplements. Yet, these antioxidative therapies to reduce oxidative stress caused by poor lifestyle, male genital tract infections/inflammations and defective spermatozoa are currently highly debated. ${ }^{144,145}$ While several studies using various antioxidants alone or in combination have shown a significant reduction in seminal ROS levels ${ }^{146-148}$ and improvement in sperm count and motility, ${ }^{149-151}$ other studies found the opposite. ${ }^{152,153}$

These apparently inconclusive results could be due to three reasons: Firstly, it is not only the administration of singular antioxidative substances that cause the beneficial effects, but the combination of different antioxidants at very specific concentrations. Secondly, normally no specific examinations of the redox status of such patients are carried out and therefore the redox status in these patients is unknown. Thirdly, due to the lack of information about the redox status, uncontrolled antioxidative treatment could then even be detrimental to the patient. The latter is attributable to the paradoxical effect of antioxidants, called the 'antioxidant paradox' ${ }^{154}$ This principle means that on the one hand, a certain amount of antioxidants is essential for normal cell function because cells generally function in a reduced state. On the other hand, however, a certain limited and localized level of ROS is also essential for cell function, for example, for normal function of several gene transcription factors ${ }^{155}$ or the induction of sperm capacitation, hyperactivity and acrosome reaction. ${ }^{156}$ In addition, apoptosis is accompanied by a shift towards a more oxidized status of the cell since caspases, as cysteine proteases, are sensitive to the redox status of the cell. Thus, changes to the intracellular redox status can either trigger or inhibit apoptosis. ${ }^{157}$ Accordingly, the uncontrolled treatment with antioxidants can worsen conditions and even be a cause of cancer ${ }^{154}$ or in the case of male infertility the reason for failed fertilization.

\section{CONCLUSIONS: BALANCE BETWEEN OXIDANTS AND ANTIOXIDANTS}

Considering the apparent possibility of dual, opposing functions of both leukocytes and ROS on sperm functions and therefore on male fertility, we have to accept the concept that ROS not only have detrimental effects on sperm functions, but also beneficial effects in terms of triggering essential cellular functions, probably in both spermatozoa and oocytes. For spermatozoa, this positive effect of ROS has been shown convincingly. Hence, a balance between ROS generation and scavenging, i.e., antioxidative capacity, is of critical importance for the physiology and functioning as well as the pathophysiology of these cells. ${ }^{43,156,158}$ While the evidence for the impact of ROS is clear at the moment, it is still under debate whether or not leukocytes might have direct beneficial effects on human sperm functions.

This has serious consequences for andrological diagnostics as well as for the treatment of male infertility. With regard to the andrological diagnostics, it is certainly not sufficient just to rely on the so-called classical sperm parameters, sperm concentration, motility and normal sperm morphology. In addition to some sperm function tests, the determination of the seminal redox status appears to be the way forward. This would then have to include the determination of ROS levels as well as the antioxidant capacity present in the ejaculate. ${ }^{132,133}$ This concept also explains the inconsistency reported in the literature about the impact and importance of ROS as well as that of leukocytes. It is therefore not sufficient just to measure only one parameter, the ROS levels or the seminal TAC, because both parameters may vary between different patients. For example, a patient might have high numbers of leukocytes present in the ejaculate, but if this patients also shows high levels of TAC, his fertility might not be compromised. On the other hand, a patient might have low numbers of activated seminal leukocytes, but very low TAC levels which do not scavenge ROS production sufficiently. As a result, this patient might be infertile. Thus, for spermatozoa this system is like a 'tightrope walk'; they will not have 
functional competence if the system of seminal oxidants and antioxidants as a whole deviates to either side; it has to be finely balanced in order to function properly.

With regard to clinical treatment of patients with antioxidant, this concept requires clinicians to carefully choose patients that can benefit from antioxidative treatment. It is not enough just to treat the patient with antioxidants, but oxidative status and TAC must be evaluated first. The same care should be taken if sperm separation medium or insemination medium is supplemented with antioxidants. In instances where such determinations are not being done first, patients will not necessarily benefit from such treatment. In contrast, it can even cause harm.

\section{COMPETING FINANCIAL INTERESTS}

The author declares no competing financial interests.

1 MacLeod J. The role of oxygen in the metabolism and motility of human spermatozoa. Am J Physiol 1943; 138: 512-8.

2 Aitken RJ, Krausz C. Oxidative stress, DNA damage and the $Y$ chromosome. Reproduction 2001; 122: 497-506.

3 Lewis SE, Aitken RJ. DNA damage to spermatozoa has impacts on fertilization and pregnancy. Cell Tissue Res 2005; 322: 33-41.

4 Zini A, Boman JM, Belzile E, Ciampi A. Sperm DNA damage is associated with an increased risk of pregnancy loss after IVF and ICSI: systematic review and metaanalysis. Hum Reprod 2008; 23: 2663-8.

5 Aitken RJ, Clarkson JS. Cellular basis of defective sperm function and its association with the genesis of reactive oxygen species by human spermatozoa. J Reprod Fertil 1987; 81: 459-69.

6 Iwasaki A, Gagnon C. Formation of reactive oxygen species in spermatozoa of infertile patients. Fertil Steril 1992; 57: 409-16.

7 Agarwal A, Ikemoto I, Loughlin KR. Relationship of sperm parameters with levels of reactive oxygen species in semen specimens. J Urol 1994; 152: 107-10.

8 Lopes S, Jurisicova A, Sun JG, Casper RF. Reactive oxygen species: potential cause for DNA fragmentation in human spermatozoa. Hum Reprod 1998; 13: 896-900.

9 Henkel R, Hajimohammad M, Stalf T, Hoogendijk C, Mehnert C et al. Influence of deoxyribonucleic acid damage on fertilization and pregnancy. Fertil Steril 2004; 81: 965-72.

10 Williams AC, Ford WC. Relationship between reactive oxygen species production and lipid peroxidation in human sperm suspensions and their association with sperm function. Fertil Steril 2005; 83: 929-36.

11 de Lamirande E, Gagnon C. Human sperm hyperactivation and capacitation as parts of an oxidative process. Free Radical Biol Med 1993; 14: 157-66.

12 de Lamirande E, Gagnon C. A positive role for the superoxide anion in triggering hyperactivation and capacitation of human spermatozoa. Int J Androl 1993; 16: 21-5.

13 Aitken RJ, Paterson M, Fisher H, Buckingham DW, van Duin M. Redox regulation of tyrosine phosphorylation in human spermatozoa and its role in the control of human sperm function. J Cell Sci 1995; 108: 2017-25.

14 Aitken RJ, Harkiss D, Knox W, Paterson M, Irvine DS. A novel signal transduction cascade in capacitating human spermatozoa characterised by a redox-regulated, cAMP-mediated induction of tyrosine phosphorylation. J Cell Sci 1998; 111: 64556.

15 de Lamirande E, O'Flaherty C. Sperm activation: role of reactive oxygen species and kinases. Biochim Biophys Acta 2008; 1784: 106-15.

16 Dröge W. Free radicals in the physiological control of cell function. Physiol Rev 2002; 82: 47-95.

17 Sen CK. Cellular thiols and redox-regulated signal transduction. Curr Top Cell Regul 2000; 36: 1-30.

18 Filomeni G, Rotilio G, Ciriolo MR. Disulfide relays and phosphorylative cascades: partners in redox-mediated signalling pathways. Cell Death Differ 2005; 12: 155563.

19 Hess ML, Manson NH. Molecular oxygen: friend and foe. The role of the oxygen free radical system in the calcium paradox, the oxygen paradox and ischemia/reperfusion injury. J Mol Cell Cardiol 1984; 16: 969-85.

20 Greabu M, Battino M, Mohora M, Olinescu R, Totan A et al. Oxygen, a paradoxical element? Rom J Intern Med 2008; 46: 125-35.

21 Cummins JM, Woodall PF. On mammalian sperm dimensions. J Reprod Fertil 1985; 75: $153-75$.

22 Maree L, du Plessis SS, Menkveld R, van der Horst G. Morphometric dimensions of the human sperm head depend on the staining method used. Hum Reprod; e-pub ahead of print 17 April 2010; doi: 10.1093/humrep/deq075.

23 Buhr MM, Curtis EF, Kakuda NS. Composition and behavior of head membrane lipids of fresh and cryopreserved boar sperm. Cryobiology 1994; 31: 224-38.
24 Flesch FM, Gadella BM. Dynamics of the mammalian sperm plasma membrane in the process of fertilization. Biochim Biophys Acta 2000; 1469: 197-235.

25 Aitken RJ, Clarkson JS, Hargreave TB, Irvine DS, Wu FC. Analysis of the relationship between defective sperm function and the generation of reactive oxygen species in cases of oligozoospermia. J Androl 1989; 10: 214-20.

26 Aitken RJ, Irvine DS, Wu FC. Prospective analysis of sperm-oocyte fusion and reactive oxygen species generation as criteria for the diagnosis of infertility. Am J Obstet Gynecol 1991; 164: 542-51.

27 Zalata AA, Christophe AB, Depuydt CE, Schoonjans F, Comhaire FH. White blood cells cause oxidative damage to the fatty acid composition of phospholipids of human spermatozoa. Int J Androl 1998; 21: 154-62.

28 Hall JC, Hadley J, Doman T. Correlation between changes in rat sperm membrane lipids, protein, and the membrane physical state during epididymal maturation. J Androl 1991; 12: 76-87.

29 Force A, Grizard G, Giraud MN, Motta C, Sion B et al. Membrane fluidity and lipid content of human spermatozoa selected by swim-up method. Int J Androl 2001; 24: 327-34.

30 Gulaya NM, Margitich VM, Govseeva NM, Klimashevsky VM, Gorpynchenko II et al. Phospholipid composition of human sperm and seminal plasma in relation to sperm fertility. Arch Androl 2001; 46: 169-75.

31 Parks JE, Lynch DV. Lipid composition and thermotropic phase behavior of boar, bull, stallion, and rooster sperm membranes. Cryobiology 1992; 29: 255-66.

32 Zalata AA, Christophe AB, Depuydt CE, Schoonjans F, Comhaire FH. The fatty acid composition of phospholipids of spermatozoa from infertile patients. Mol Hum Reprod 1998; 4: 111-8.

33 Sanocka D, Kurpisz M. Reactive oxygen species and sperm cells. Reprod Biol Endocrinol 2004; 2: 12.

34 Lenzi A, Gandini L, Maresca V, Rago R, Sgro P et al. Fatty acid composition of spermatozoa and immature germ cells. Mol Hum Reprod 2000; 6: 226-31.

35 Tavilani H, Doosti M, Abdi K, Vaisiraygani A, Joshaghani HR. Decreased polyunsaturated and increased saturated fatty acid concentration in spermatozoa from asthenozoospermic males as compared with normozoospermic males. Andrologia 2006; 38: 173-8

36 Haidl G, Opper C. Changes in lipids and membrane anisotropy in human spermatozoa during epididymal maturation. Hum Reprod 1997; 12: 2720-3.

37 Ollero M, Gil-Guzman E, Lopez MC, Sharma RK, Agarwal A et al. Characterization of subsets of human spermatozoa at different stages of maturation: implications in the diagnosis and treatment of male infertility. Hum Reprod 2001; 16: 1912-21.

38 Khosrowbeygi A, Zarghami N. Fatty acid composition of human spermatozoa and seminal plasma levels of oxidative stress biomarkers in subfertile males. Prostaglandins Leukot Essent Fatty Acids 2007; 77: 117-21.

39 Koppers AJ, Garg ML, Aitken RJ. Stimulation of mitochondrial reactive oxygen species production by unesterified, unsaturated fatty acids in defective human spermatozoa. Free Radic Biol Med 2010; 48: 112-9.

40 Halliwell B, Gutteridge JMC. Free Radicals in Biology and Medicine. 2nd ed. Oxford: Clarendon Press; 1989.

41 Tosic J, Walton A. Formation of hydrogen peroxide by spermatozoa and its inhibitory effects on respiration. Nature 1946; 158: 485.

42 Tosic J, Walton A. Metabolism of spermatozoa: the formation and elimination of hydrogen peroxide by spermatozoa and effects on motility and survival. Biochem $J$ 1950; 47: 199-212.

43 de Lamirande E, Gagnon C. Impact of reactive oxygen species on spermatozoa: a balancing act between beneficial and detrimental effects. Hum Reprod 1995; 10(Suppl 1): 15-21.

44 Griveau JF, Dumont E, Renard P, Callegari JP, le Lannou D. Reactive oxygen species, lipid peroxidation and enzymatic defence systems in human spermatozoa. J Reprod Fertil 1995; 103: 17-26.

45 Storey BT. Mammalian sperm metabolism: oxygen and sugar, friend and foe. Int J Dev Biol 2008; 52: 427-437.

46 Caldwell K, Blake ET, Sensabaugh GF. Sperm diaphorase: genetic polymorphism and a sperm-specific enzyme in man. Science 1976; 191: 1185-7.

47 Gavella M, Lipovac V. NADH-dependent oxidoreductase (diaphorase) activity and isozyme pattern of sperm in infertile men. Arch Androl 1992; 28: 135-41.

48 Andreyev AY, Kushnareva YE, Starkov AA. Mitochondrial metabolism of reactive oxygen species. Biochemistry (Mosc) 2005; 70: 200-14.

49 Koppers AJ, de Iuliis GN, Finnie JM, McLaughlin EA, Aitken RJ. Significance of mitochondrial reactive oxygen species in the generation of oxidative stress in spermatozoa. J Clin Endocrinol Metab 2008; 93: 3199-207.

50 Finkel T, Holbrook NJ. Oxidants, oxidative stress and the biology of ageing. Nature 2000; 408: 239-47.

51 Boveris A, Chance B. The mitochondrial generation of hydrogen peroxide. General properties and effect of hyperbaric oxygen. Biochem J 1973; 134: 707-16.

52 Chance B, Sies H, Boveris H. Hydroperoxide metabolism in mammalian organs. Physiol Rev 1979; 59: 527-605.

53 Raha S, Robinson BH. Mitochondria, oxygen free radicals and aging. Trends Biochem Sci 2000; 25: 502-8.

54 Gomez E, Buckingham D, Brindle J, Lanzafame F, Irvine DS et al. Development of an image analysis system to monitor the retention of residual cytoplasm by human spermatozoa: correlation with biochemical markers of the cytoplasmic space, oxidative stress and sperm function. J Androl 1996; 17: 276-87.

55 Keating J, Grundy CE, Fivey PS, Elliott M, Robinson J. Investigation of the association between the presence of cytoplasmic residues on the human sperm midpiece and defective sperm function. J Reprod Fertil 1997; 110: 71-7. 
56 Aitken RJ, Fisher HM, Fulton N, Gomez E, Knox W, et al. Reactive oxygen species generation by human spermatozoa is induced by exogenous NADPH and inhibited by the flavoprotein inhibitors diphenylene iodonium and quinacrine. Mol Reprod Dev 1997; 47: 468-82.

57 Aziz N, Saleh RA, Sharma RK, Lewis-Jones I, Esfandiari N et al. Novel association between sperm reactive oxygen species production, sperm morphological defects, and the sperm deformity index. Fertil Steril 2004; 81: 349-54.

58 Gil-Guzman E, Ollero M, Lopez MC, Sharma RK, Alvarez JG et al. Differential production of reactive oxygen species by subsets of human spermatozoa at different stages of maturation. Hum Reprod 2001; 16: 1922-30.

59 Henkel R, Kierspel E, Hajimohammad M, Stalf T, Hoogendijk C et al. DNA fragmentation of spermatozoa and assisted reproduction technology. RBM Online 2003; 7: 44-51.

60 Plante M, de Lamirande E, Gagnon C. Reactive oxygen species released by activated neutrophils, but not by deficient spermatozoa, are sufficient to affect normal sperm motility. Fertil Steril 1994; 62: 387-93.

61 de Lamirande E, Gagnon C. Capacitation-associated production of superoxide anion by human spermatozoa. Free Rad Biol Med 1995; 18: 487-95.

62 Wolff H. The biologic significance of white blood cells in semen. Fertil Steril 1995; 63 1143-57.

63 Henkel R, Schill WB. Sperm separation in patients with urogenital infections. Andrologia 1998; 30(Suppl 1): 91-7.

64 Sanocka-Maciejewska D, Ciupinska M, Kurpisz M. Bacterial infection and semen quality. J Reprod Immunol 2005; 67: 51-6.

65 Weidner W, Colpi GM, Hargreave TB, Papp GK, Pomerol JM et al. EAU guidelines on male infertility. Eur Urol 2002; 42: 313-22.

66 Schuppe HC, Meinhardt A, Allam JP, Bergmann M, Weidner W et al. Chronic orchitis: a neglected cause of male infertility? Andrologia 2008; 40: 84-91.

67 Monga M, Roberts JA. Spermagglutination by bacteria: receptor-specific interactions. $J$ Androl 1994; 15: 151-6.

68 Eggert-Kruse W, Kiefer I, Beck C, Demirakca T, Strowitzki T. Role for tumor necrosis factor alpha (TNF-alpha) and interleukin 1-beta (IL-1beta) determination in seminal plasma during infertility investigation. Fertil Steril 2007; 87: 810-23.

69 Henkel R, Maass G, Jung A, Haidl G, Schill WB et al. Age-related changes in seminal polymorphonuclear elastase in men with asymptomatic inflammation of the genital tract. Asian J Androl 2007; 9: 299-304.

70 Moretti E, Capitani S, Figura N, Pammolli A, Federico MG et al. The presence of bacteria species in semen and sperm quality. J Assist Reprod Genet 2009; 26: 47 56.

71 Martinez R, Proverbio F, Camejo MI. Sperm lipid peroxidation and pro-inflammatory cytokines. Asian J Androl 2007; 9: 102-7.

72 Mortimer D. Sperm preparation techniques and iatrogenic failures of in-vitro fertilization. Hum Reprod 1991; 6: 173-6.

73 Köhn FM, Erdmann I, Oeda T, el Mulla KF, Schiefer HG et al. Influence of urogenital infections on sperm functions. Andrologia 1998; 30(Suppl 1): 73-80.

74 Alvarez JG, Sharma RK, Ollero M, Saleh RA, Lopez MC et al. Increased DNA damage in sperm from leukocytospermic semen samples as determined by the sperm chromatin structure assay. Fertil Steril 2002; 78: 319-29.

75 Henkel R, Kierspel E, Stalf T, Mehnert C, Menkveld R et al. Effect of reactive oxygen species produced by spermatozoa and leukocytes on sperm functions in nonleukocytospermic patients. Fertil Steril 2005; 83: 635-42.

76 Henkel R, Ludwig M, Schuppe HC, Diemer T, Schill WB et al. Chronic pelvic pain syndrome/chronic prostatitis affect the acrosome reaction in human spermatozoa. World J Urol 2006; 24: 39-44.

77 Zalata AA, Ahmed AH, Allamaneni SS, Comhaire FH, Agarwal A. Relationship between acrosin activity of human spermatozoa and oxidative stress. Asian J Androl 2004; 6 : 313-8.

78 Menge AC, Edwards RP. Mucosal immunity of the reproductive tract and infertility. In: Zaz RK, editors. Immunology of Reproduction. Boca Raton, FL: CRC Press; 1993. pp19-36.

79 Lovaas E, Carlin G. Spermine: an anti-oxidant and anti-inflammatory agent. Free Radical Biol Med 1991; 11: 455-61.

$80 \mathrm{Ha} \mathrm{HC}$, Sirisoma NS, Kuppusamy P, Zweier JL, Woster PM et al. The natural polyamine spermine functions directly as a free radical scavenger. Proc Natl Acad Sci USA 1998 95: 11140-5.

81 Lundwall A, Giwercman A, Ruhayel Y, Giwercman Y, Lilja $\mathrm{H}$ et al. A frequent allele codes for a truncated variant of semenogelin I, the major protein component of human semen coagulum. Mol Hum Reprod 2003; 9: 345-50.

82 Bourgeon F, Evrard B, Brillard-Bourdet M, Colleu D, Jegou B et al. Involvement of semenogelin-derived peptides in the antibacterial activity of human seminal plasma. Biol Reprod 2004; 70: 768-74.

83 Settlage DSF, Motoshima M, Tredway DR. Sperm transport from the external cervical os to the fallopian tubes in women: a time and quantitative study. Fertil Steril 1973; 24: 655-61.

84 Rhemrev JP, van Overveld FW, Haenen GR, Teerlink T, Bast A et al. Quantification of the nonenzymatic fast and slow TRAP in a post addition assay in human seminal plasma and the antioxidant contributions of various seminal compounds. J Androl 2000; 21: 913-20.

85 Suarez SS, Pacey AA. Sperm transport in the female reproductive tract. Hum Reprod Update 2006; 12: 23-37

86 Navarrete Gomez P, Espinoza Ruiz J, Parodi Rivera J, Alvarez JG, Sanchez Gutierrez R. Protective effect of fallopian tubal fluid against activated leucocyte-induced sperm DNA fragmentation: preliminary results. Andrologia 2009; 41: 196-8.
87 Agarwal DK, Maronpot RR, Lamb JC, Kluwe WM. Adverse effects of butyl benzyl phthalate on the reproductive and hematopoietic systems of male rats. Toxicology 1985; 35: 189-06.

88 Chitra KC, Sujatha R, Latchoumycandane C, Mathur PP. Effect of lindane on antioxidant enymes in epididymis and epididymal sperm of adult rats. Asian Androl 2001; 3: 205-8.

89 Meng Z, Bai W. Oxidation damage of sulfur dioxide on testicles of mice. Environ Res 2004: 96: 298-304.

90 Saleh RA, Agarwal A, Sharma RK, Nelson DR, Thomas AJ Jr. Effect of cigarette smoking on levels of seminal oxidative stress in infertile men: a prospective study. Fertil Steril 2003; 78: 491-9.

91 Das SK, Vasudevan DM. Alcohol-induced oxidative stress. Life Sci 2007; 81: 177 87

92 de Lamirande E, Leduc BE, Iwasaki A, Hassouna M, Gagnon C. Increased reactive oxygen species formation in semen of patients with spinal cord injury. Fertil Steril 1995; 63: 637-42.

93 Hendin BN, Kolettis PN, Sharma RK, Thomas AJ Jr, Agarwal A. Varicocele is associated with elevated spermatozoal reactive oxygen species production and diminished seminal plasma antioxidant capacity. J Urol 1999; 161: 1831-4.

94 Tavilani H, Goodarzi MT, Doosti M, Vaisi-Raygani A, Hassanzadeh T et al. Relationship between seminal antioxidant enzymes and the phospholipid and fatty acid composition of spermatozoa. Reprod Biomed Online 2008; 16: 649-56.

95 Sies H, Stahl W, Sundquist AR. Antioxidant functions of vitamins. Vitamins E and C beta-carotene, and other carotenoids. Ann NY Acad Sci 1992; 669: 7-20.

96 Sies H. Oxidative stress: introductory remarks. In: Sies H, editor. Oxidative Stress. London: Academic Press; 1985. pp1-8.

97 Sikka SC, Rajasekaran M, Hellstrom WJ. Role of oxidative stress and antioxidants in male infertility. J Androl 1995; 16: 464-8.

98 Riffo MS, Parraga M. Study of the acrosome reaction and the fertilizing ability of hamster epididymal cauda spermatozoa treated with antibodies agains phospholipase A2 and/or lysophosphatidylcholine. J Exp Zool 1996; 275: 459-68.

99 Blake DR, Allen RE, Lunec J. Free radicals in biological systems. A review orientated to inflammatory processes. Br Med Bull 1987; 43: 371-85.

100 Kothari S, Thompson A, Agarwal A, du Plessis S. Free radicals: their beneficial and detrimental effects on sperm function. Indian J Exp Biol 2010; 48: 425-435.

101 Luczaj W, Skrzydlewska E. DNA damage caused by lipid peroxidation products. Cell Mol Biol Lett 2003; 8: 391-413.

102 Esterbauer H. Cytotoxicity and genotoxicity of lipid-oxidation products. Am J Clin Nutr 1993; 57(5 Suppl): 779S-85S

103 Saraniya A, Koner BC, Doureradjou P, Selvaraj N, Shivagourou V. Altered malondialdehyde, protein carbonyl and sialic acid levels in seminal plasma of microscopically abnormal semen. Andrologia 2008; 40: 56-7.

104 Zabludovsky N, Eltes F, Geva E, Berkovitz E, Amit A et al. Relationship between human sperm lipid peroxidation, comprehensive quality parameters and IVF outcome. Andrologia 1999; 31: 91-8.

105 Burcham PC. Genotoxic lipid peroxidation products: their DNA damaging properties and role in formation of endogenous DNA adducts. Mutagenesis 1998; 13: 287-305.

106 Giamarellou H, Tympanidis K, Bitos NA, Leonidas E, Daikos GK. Infertility and chronic prostatitis. Andrologia 1984; 16: 417-22.

107 Krieger JN, Berger RE, Ross SO, Rothman I, Muller CH. Seminal fluid findings in men with nonbacterial prostatitis and prostatodynia. J Androl 1996; 17: 310-8.

108 Menkveld R, Huwe P, Ludwig M, Weidner W. Morphological sperm alterations in different types of prostatitis. Andrologia 2003; 35: 288-93.

109 Stauss CR, Votta TJ, Suarez SS. Sperm motility hyperactivation facilitates penetration of the hamster zona pellucida. Biol Reprod 1995; 53: 1280-5.

110 De Lamirande E, Tsai C, Harakat A, Gagnon C. Involvement of reactive oxygen species in human sperm arcosome reaction induced by A23187, lysophosphatidylcholine, and biological fluid ultrafiltrates. J Androl 1998; 19: 585-94.

111 Griveau JF, le Lannou D. Reactive oxygen species and human spermatozoa: physiology and pathology. Int J Androl 1997; 20: 61-9.

112 Aitken RJ, Clarkson JS, Fishel S. Generation of reactive oxygen species, lipid peroxidation, and human sperm function. Biol Reprod 1989; 41: 183-97.

113 Bize I, Santander G, Cabello P, Driscoll D, Sharpe C. Hydrogen peroxide is involved in hamster sperm capacitation in vitro. Biol Reprod 1991; 44: 398-403.

114 Yeoman RR. Blockade of nitric oxide synthase inhibits hamster sperm hyperactivation. Biol Reprod 1994; 50(Suppl. 1): 104.

115 Dorval V, Dufour M, Leclerc P. Role of protein tyrosine phosphorylation in the thapsigargin-induced intracellular $\mathrm{Ca}^{2+}$ store depletion during human sperm acrosome reaction. Mol Hum Reprod 2003; 9: 125-31.

116 O'Flaherty C, de Lamirande E, Gagnon C. Reactive oxygen species modulate independent protein phosphorylation pathways during human sperm capacitation. Free Radic Biol Med 2006; 40: 1045-55.

117 O'Flaherty C, de Lamirande E, Gagnon C. Phosphorylation of the arginine-X-X-(serine/ threonine) motif in human sperm proteins during capacitation: modulation and protein kinase A dependency. Mol Hum Reprod 2004; 10: 355-63.

118 Ochsendorf FR, Thiele J, Fuchs J, Schütau H, Freileben HJ et al. Chemiluminescence in semen of infertile men. Andrologia 1994; 26: 289-93.

119 Chi HJ, Kim JH, Ryu CS, Lee JY, Park JS et al. Protective effect of antioxidant supplementation in sperm-preparation medium against oxidative stress in human spermatozoa. Hum Reprod 2008; 23: 1023-8.

120 Erenpreiss J, Hlevicka S, Zalkalns J, Erenpreisa J. Effect of leukocytospermia on sperm DNA integrity: a negative effect in abnormal semen samples. J Androl 2002 23: 717-23. 
121 Aziz N, Agarwal A, Lewis-Jones I, Sharma RK, Thomas AJ. Novel associations between specific sperm morphological defects and leukocytospermia. Fertil Steril 2004; 82: 621-7.

122 Aitken RJ, Buckingham DW, Brindle J, Gomez E, Baker HW et al. Analysis of sperm movement in relation to the oxidative stress created by leukocytes in washed sperm preparations and seminal plasma. Hum Reprod 1995; 10: 2061-71.

123 World Health Organization. WHO Laboratory Manual for the Examination and Processing of Human Semen. 5th edn. Geneva: WHO; 2010.

124 Sharma RK, Pasqualotto AE, Nelson DR, Thomas AJ Jr, Agarwal A. Relationship between seminal white blood cell counts and oxidative stress in men treated at an infertility clinic. J Androl 2001; 22: 575-83.

125 Punab M, Loivukene K, Kermes K, Mändar R. The limit of leucocytospermia from the microbiological viewpoint. Andrologia 2003; 35: 271-8.

126 Oborna I, Fingerova H, Novotny J, Brezinova J, Svobodova M et al. Reactive oxygen species in human semen in relation to leukocyte contamination. Biomed Pap Med Fac Univ Palacky Olomouc Czech Repub 2009; 153: 53-7.

127 Tomlinson MJ, Barratt CL, Cooke ID. Prospective study of leukocytes and leukocyte subpopulations in semen suggests they are not a cause of male infertility. Fertil Steril 1993; 60: 1069-75.

128 Kaleli S, Öcer F, Irez T, Budak E, Aksu MF. Does leukocytospermia associate with poor semen parameters and sperm functions in male infertility? The role of different seminal leukocyte concentrations. Eur J Obstet Gynecol Reprod Biol 2000; 89: 185-91.

129 Ziyyat A, Barraud-Lange V, Sifer C, Ducot B, Wolf JP et al. Paradoxical increase of sperm motility and seminal carnitine associated with moderate leukocytospermia in infertile patients. Fertil Steril 2008; 90: 2257-63.

130 Lackner JE, Agarwal A, Mahfouz R, du Plessis SS, Schatzl G. The association between leukocytes and sperm quality is concentration dependent. Reprod Biol Endocrinol 2010; 8: 12

131 Chakroun-Feki N, Therond P, Couturier M, Eustache F, Limea G et al. Human sperm quality and lipid content after migration into normal ovulatory human cervical mucus containing low numbers of leukocytes. Asian J Androl 2009; 11: 308-16.

132 Lewis SE, Boyle PM, McKinney KA, Young IS, Thompson W. Total antioxidant capacity of seminal plasma is different in fertile and infertile men. Fertil Steril 1995; 64: 86870.

133 Mahfouz R, Sharma R, Sharma D, Sabanegh E, Agarwal A. Diagnostic value of the total antioxidant capacity (TAC) in human seminal plasma. Fertil Steril2009; 91: 805-11.

134 Bauche F, Fouchard MH, Jegou B. Antioxidant system in rat testicular cells. FEBS Lett 1994; 349: 392-6.

135 Den Boer PJ, Poot M, Verkerk A, Jansen R, Mackenbach P et al. Glutathionedependent defence mechanisms in isolated round spermatids from the rat. Int $J$ Androl 1990; 13: 26-38.

136 Vernet P, Aitken RJ, Drevet JR. Antioxidant strategies in the epididymis. Mol Cell Endocrinol 2004; 216: 31-9.

137 Chow CK. Vitamin E and oxidative stress. Free Radical Biol Med 1991; 11: 215-32.

138 Niki E. Action of ascorbic acid as scavenger of active and stable oxygen radicals. Am J Clin Nutr 1991; 54: 1119S-24S.
139 Kobayashi T, Miyazaki T, Natori M, Nozawa S. Protective role of superoxide dismutase in human sperm motility: superoxide dismutase activity and lipid peroxide in human seminal plasma and spermatozoa. Hum Reprod 1991; 6: 987-91.

140 Grootveldt M, Halliwell B. Measurement of allantoin and uric acid in human body fluids. Biochem J 1987; 242: 803-8.

$141 \mathrm{Li} \mathrm{TK}$. The glutathione and thiol content of mammalian spermatozoa and seminal plasma. Biol Reprod 1975; 12: 641-6.

142 Drevet JR. The antioxidant glutathione peroxidase family and spermatozoa: a complex story. Mol Cell Endocrinol 2006; 250: 70-9.

143 El Mouatassim S, Guerin P, Menezo Y. Mammalian oviduct and protection against free oxygen radicals: expression of genes encoding antioxidant enzymes in human and mouse. Eur J Obstet Gynecol Reprod Biol 2000; 89: 1-6.

144 Tremellen K. Oxidative stress and male infertility-a clinical perspective. Hum Reprod Update 2008; 14: 243-58.

145 Lanzafame FM, la Vignera S, Vicari E, Calogero AE. Oxidative stress and medical antioxidant treatment in male infertility. Reprod Biomed Online 2009; 19: 638-59.

146 Comhaire FH, Christophe AB, Zalata AA, Dhooge WS, Mahmoud AM et al. The effects of combined conventional treatment, oral antioxidants and essential fatty acids on sperm biology in subfertile men. Prostaglandins Leukot Essent Fatty Acids 2000; 63: 159-65.

147 Comhaire FH, el Garem Y, Mahmoud A, Eertmans F, Schoonjans F. Combined conventional/antioxidant 'Astaxanthin' treatment for male infertility: a double blind, randomized trial. Asian J Androl 2005; 7: 257-62.

148 Vicari E, Calogero AE. Effects of treatment with carnitines in infertile patients with prostato-vesiculo-epididymitis. Hum Reprod 2001; 16: 2338-42.

149 Lenzi A, Sgro P, Salacone P, Paoli D, Gilio B, Lombardo F et al. A placebo-controlled double-blind randomized trial of the use of combined I-carnitine and I-acetyl-carnitine treatment in men with asthenozoospermia. Fertil Steril 2004; 81: 1578-84.

150 Balercia G, Regoli F, Armeni T, Koverech A, Mantero F et al. Placebo-controlled double-blind randomized trial on the use of L-carnitine, L-acetylcarnitine, or combined L-carnitine and L-acetylcarnitine in men with idiopathic asthenozoospermia. Fertil Steril 2005; 84: 662-71.

151 Akmal M, Qadri JQ, Al-Waili NS, Thangal S, Haq A et al. Improvement in human semen quality after oral supplementation of vitamin C. J Med Food 2006; 9: 440-2.

152 Greco E, lacobelli M, Rienzi L, Ubaldi F, Ferrero S et al. Reduction of the incidence of sperm DNA fragmentation by oral antioxidant treatment. J Androl 2005; 26: 349-53.

153 Menezo YJ, Hazout A, Panteix G, Robert F, Rollet J et al. Antioxidants to reduce sperm DNA fragmentation: an unexpected adverse effect. Reprod Biomed Online 2007; 14: 418-21.

154 Halliwell B. The antioxidant paradox. Lancet 2000; 355: 1179-80.

155 Sen CK. Redox signalling and the emerging therapeutic potential of thiol antioxidants. Biochem Pharmacol 1998; 55: 1747-58.

156 Aitken J, Fisher $\mathrm{H}$. Reactive oxygen species generation and human spermatozoa: the balance of benefit and risk. Bioessays 1994; 16: 259-67.

157 Hampton MB, Orrenius S. Redox regulation of apoptotic cell death. Biofactors 1998; 8: $1-5$.

158 Kothari S, Thompson A, Agarwal A, du Plessis S. Free radicals: their beneficial and detrimental effects on sperm function. Indian J Exp Biol 2010; 48: 425-35. 